\title{
Het afnemen van de Van Wiechenkenmerken door ouders
}

\section{Een pilotonderzoek}

\author{
M. Grevinga $\cdot$ L. V. van Harten · H. Hofstetter $\cdot$ P. H. Verkerk · S. B. Detmar
}

Published online: 24 April 2018

(C) Bohn Stafleu van Loghum is een imprint van Springer Media B.V., onderdeel van Springer Nature 2018

\begin{abstract}
Samenvatting Tijdens reguliere contactmomenten van de jeugdgezondheidszorg (JGZ) wordt het Van Wiechenonderzoek door professionals afgenomen om de ontwikkeling van kinderen te volgen. Vanwege de aandacht voor zelfmanagement en het vergroten van de betrokkenheid van ouders bij de JGZ is in deze pilotstudie gekeken of ouders in staat zijn de Van Wiechenkenmerken af te nemen. De gegevens zijn verzameld aan de hand van vragenlijsten bij 211 kinderen $(n=305$, response $=69 \%$, hoogopgeleide ouders $=59 \%$ ) van contactmomenten 1-15 maanden. Van de bijbehorende 38 Van Wiechenkenmerken zijn er 28 geselecteerd. Hierbij wordt gekeken naar de ervaringen van ouders met het zelf afnemen van de kenmerken en de overeenkomst in de scores van ouder en professional op de geselecteerde Van Wiechenkenmerken. $92 \%$ van de ouders gaf aan plezier te hebben in het afnemen van alle kenmerken. De proportionele overeenkomst op de kenmerken in de steekproef laat een hoge overeenkomst zien op de communicatiekenmerken en een wat lagere overeenkomst op de grove motoriekkenmerken. Een vervolgstudie met een grotere steekproef is nodig om dit daadwerkelijk vast te stellen.
\end{abstract}

Trefwoorden Ontwikkeling • Van Wiechenonderzoek . Afnemen door ouders · Zelfafname · D-score

M. Grevinga $(\bowtie) \cdot$ L. V. van Harten $\cdot$ H. Hofstetter P. H. Verkerk · S. B. Detmar

Afdeling Child Health, Nederlandse organisatie voor toegepast- natuurwetenschappelijk onderzoek (TNO), Leiden, Nederland

manon.grevinga@tno.nl

\section{Inleiding}

Tijdens de reguliere contactmomenten van de jeugdgezondheidszorg (JGZ) wordt de ontwikkeling van het kind gevolgd door middel van het Van Wiechenonderzoek [1]. Afhankelijk van de leeftijd van het kind wordt een bepaalde set Van Wiechenkenmerken afgenomen. Kenmerken worden afgenomen op een leeftijd waarop $90 \%$ van de kinderen het betreffende kenmerk toont. Om de ontwikkeling van kinderen objectief te kunnen interpreteren en vergelijken ontwikkelden Jacobusse et al. [2, 3] de Developmental-score (D-score): een samenvattende maat die een globale ontwikkelingsscore geeft op basis van de Van Wiechenkenmerken. Het Van Wiechenonderzoek bestaat uit 74 ontwikkelingskenmerken verdeeld over drie ontwikkelingsvelden: fijne motoriek/adaptie/persoonlijkheid/sociaal gedrag, communicatie en grove motoriek. De doelstellingen van het Van Wiechenonderzoek zijn [4]: (1) Het begeleiden van de ontwikkeling van het jonge kind ( $0-4$ jaar) en het hierbij zo goed mogelijk betrekken van de ouders; en (2) Het vroegtijdig opsporen van ontwikkelingsproblemen en -stoornissen en het ondersteunen van verwijzing.

Het zelf afnemen van de Van Wiechenkenmerken kan mogelijk bijdragen aan het betrekken van de ouders bij de ontwikkeling van hun kind. Rydz et al. beschreven eerder dat het actief betrekken van ouders bij screening, kan leiden tot een meer proactieve kijk op de ontwikkeling van hun kind [5]. Bovendien zijn er aanwijzingen dat oudervragenlijsten even accuraat zijn voor de screening van ontwikkelingsachterstanden als screening door professionals $[6,7]$. Ook toont onderzoek aan dat ouders in staat zijn accurate informatie over de ontwikkeling van het kind te geven [8-10]. Op dit moment zijn er echter geen studies bekend waarbij gekeken is of ouders zelf de Van Wiechenkenmerken kunnen afnemen. 
Het huidige pilotonderzoek richt zich op de haalbaarheid om het Van Wiechenonderzoek ook (deels) door ouders zelf af te laten nemen. Daarnaast wilden we een eerste indruk verkrijgen van de mate van overeenstemming tussen afname door ouders en afname door professionals. Dit onderzoek is uitgevoerd in samenwerking met GGD Hollands Midden. De volgende onderzoeksvragen worden beantwoord:

1. Wat zijn de ervaringen van ouders met het zelf afnemen van de geselecteerde Van Wiechenkenmerken?

2. Komen de scores van ouders en van professionals overeen op de geselecteerde Van Wiechenkenmerken?

\section{Methode}

\section{Selectie van de Van Wiechenkenmerken}

Doordat enkele items door de onderzoekers niet geschikt werden bevonden voor thuisafname, is ervoor gekozen een selectie van kenmerken van het Van Wiechenonderzoek te onderzoeken. De contactmomenten (en bijhorende Van Wiechenkenmerken) van 4 weken, 8 weken, 13 weken, 26 weken, 39 weken, 52 weken en 65 weken zijn in het onderzoek meegenomen. Deze contactmomenten hebben in totaal 38 Van Wiechenkenmerken waarvan er 28 zijn geselecteerd. Twee kenmerken ('beweegt armen evenveel' en 'beweegt benen evenveel') worden op zes van deze zeven contactmomenten onderzocht.

Van de geselecteerde kenmerken zijn er 15 mededeling-kenmerken ('M-kenmerken'): kenmerken waarbij de professional op het antwoord van de ouder(s) af mag gaan. Er mag dus vanuit worden gegaan dat ouders in staat zijn om deze M-kenmerken te beoordelen/uitvoeren. Daarnaast zijn er 13 kenmerken geselecteerd op basis van de volgende criteria: de uitvoering door ouders mag geen gevaar voor het kind opleveren, moet door een persoon uitgevoerd kunnen worden en de materialen die nodig zijn, moeten redelijkerwijs in ieder huis aanwezig zijn.

Belangrijk om hierbij aan te geven, is dat de tien niet-geselecteerde van Wiechenkenmerken ook van belang zijn bij de evaluatie van de ontwikkeling van het kind. Als kinderen een of meerdere kenmerken niet beheersen op de in het Van Wiechenschema aangegeven leeftijd, kan dat een indicatie zijn voor een ontwikkelingsachterstand. Omdat het huidige onderzoek een pilotstudie betreft en omdat de D-score een maat is voor de globale ontwikkeling, is ervoor gekozen om een selectie van de Van Wiechenkenmerken te gebruiken.

Voorafgaand aan het onderzoek is gekeken of de D-score die wordt berekend met enkel de geselecteerde kenmerken, samenhangt met de D-score berekend met alle kenmerken op basis van data van de SMOCK-studie [11]. In deze studie is onder andere data over de eerste twee levensjaren verzameld door professionals van 21 consultatiebureaus. Er werd een sterke samenhang $(\mathrm{r}=1,00)$ gevonden, wat erop wijst dat de D-score ook goed te benaderen is met deze selectie van items. Deze zeer sterke samenhang is te verklaren door de methodologie achter de D-score, die het toestaat om de D-score betrouwbaar te schatten met een beperkt aantal kenmerken. Een groter aantal kenmerken zal leiden tot een preciezere schatting van de D-score.

\section{Dataverzameling}

Data zijn gedurende 4 maanden (half oktober 2016 tot en met februari 2017) verzameld door vier teams van GGD Hollands Midden. Vanaf de start van de dataverzameling werden alle ouders waarmee een afspraak was gepland, uitgenodigd om mee te doen met het onderzoek. Vanwege de beperkte opzet van de studie, werden maximaal 15 ouders per contactmoment door elk team uitgenodigd. De studie was cross-sectioneel en ouders werden maar op een contactmoment uitgenodigd. Deelnemende ouders gaven geïnformeerde toestemming en werden verzocht de vragenlijst zo kort mogelijk voor het contactmoment in te vullen. De ouders kregen geen uitslag van de score en op het contactmoment was er, zoals gebruikelijk, ruimte om vragen te stellen aan de professional.

De vragenlijsten voor de ouders zijn ontwikkeld op basis van het handboek 'Ontwikkelingsonderzoek in de jeugdgezondheidszorg: Het Van Wiechenonderzoek - De Baeacke-Fassaert Motoriektest' [4] en de instructies zijn vertaald naar B1-niveau Nederlands. Voor sommige kenmerken waren meerdere vragen nodig die allemaal met 'ja' beantwoord moesten worden voor een positieve score. Dit betrof kenmerken waarbij de kwaliteit van de uitvoer van het kenmerk van belang is. Daarnaast is aan ouders, in dezelfde vragenlijst, gevraagd naar hun ervaringen via gesloten en open vragen. Bij elke gesloten vraag was ook ruimte voor suggesties en/of opmerkingen. Ouders hadden de keuze tussen een papieren en een digitale, online vragenlijst die per leeftijdsgroep was opgesteld. Het contactmoment bij de professional verliep zoals gebruikelijk, waarbij de professional de scores op de Van Wiechenkenmerken noteerde in het Digitaal Dossier JGZ. Na afloop van de dataverzamelingsperiode werden de scores van de professional en de vragenlijsten van de ouder(s) gekoppeld op basis van een nietherleidbare code en geboortedatum van het kind.

\section{Analyses}

De ervaringen van ouders werden aan de hand van beschrijvende statistiek geanalyseerd. Voor het onderzoeken van de overeenkomst in de scores tussen ouder en professional op de Van Wiechenkenmerken wordt gebruikt gemaakt van de proportionele overeenkomst per kenmerk. Daarnaast wordt gebruik gemaakt van de D-score: een samenvattende maat op de schaal van 0-70 voor kinderen tot 2,5 jaar [3]. Door de D-score 
te berekenen met alleen de geselecteerde kenmerken, zullen deze lager uitvallen dan de gerapporteerde gemiddelden in Jacobusse et al. [3]. In dit onderzoek worden de D-scores berekend met de geselecteerde kenmerken met uitzondering van de 'alarmsymptomen' ('beweegt armen evenveel' en 'beweegt benen evenveel'). Deze twee kenmerken zijn minder relevant voor de ontwikkeling van het kind, omdat ze niet leeftijdsgebonden zijn: kinderen zouden dit kenmerk op iedere leeftijd moeten tonen. Voor zes kinderen ontbraken de scores van de ouder en/of professional voor alle overige kenmerken voor die leeftijd die nodig waren voor het berekenen van de D-score.

Vaak wordt de correlatiecoëfficiënt (r) gebruikt als maat voor overeenkomst. Nadeel van $r$ is echter dat deze maat geen rekening houdt met systematische afwijkingen tussen beoordelaars [12]. Bovendien blijkt de hoogte van $r$ gevoelig te zijn voor de verdeling van de waarden op de $\mathrm{x}$ - en y-as. Vandaar dat de overeenkomst in D-scores, berekend op basis van de antwoorden van ouders en professional, onderzocht is door middel van de Bland-Altman plot [13] en de bijbehorende 'limieten van de overeenkomst'. Deze plot geeft inzicht of een relatie tussen de meetfout en de echte waarde bestaat, en de klinische relevantie van de 'limieten van de overeenkomst' geven inzicht in de overeenkomst in D-scores tussen ouder en professional. Om de 'limieten van de overeenkomst' vast te stellen moeten de verschillen normaal verdeeld zijn. $\mathrm{Na}$ het raadplegen van het histogram van de verschillen (niet bijgevoegd) is geconcludeerd dat de verschillen niet normaal verdeeld zijn. Om toch een inzicht te krijgen in de limieten van de overeenkomst maken we gebruik van bootstrapping [14]. Met deze methode worden 500 nieuwe datasets gemaakt, ter grootte van de steekproef, bestaande uit willekeurig getrokken observaties (met teruglegging) van de steekproef. Voor elk van deze 500 datasets worden de limieten van de overeenkomst berekend door tweemaal de standaarddeviatie op te tellen en af te trekken van het gemiddelde. De limieten van de overeenkomst worden samengevat door het gemiddelde en het betrouwbaarheidsinterval over deze 500 datasets.

\section{Resultaten}

\section{Steekproef}

In totaal werden 305 ouders uitgenodigd, waarvan $211(69 \%)$ meededen met het onderzoek. De verdeling van deze ouders per contactmoment: 4 weken: $n=36$; 8 weken: $n=29$; 13 weken: $n=37$; 26 weken: $n=36$; 39 weken: $n=10$; 52 weken: $n=25$; 65 weken: $n=38$. Er deden voornamelijk moeders (90\%) mee en de respondenten waren veelal hoogopgeleid (59\%). Voor het beantwoorden van de eerste onderzoeksvraag, omtrent de ervaringen van ouders, zijn alleen de vragenlijsten van de ouders relevant en is de steekproefgrootte 211 respondenten.
Voor de steekproef voor de tweede onderzoeksvraag, waarin de overeenkomst (in D-score) wordt onderzocht, is koppeling van de scores van ouders en professionals noodzakelijk. Data van 12 kinderen zijn geëxcludeerd, omdat bij het koppelen de geboortedatum niet overeen kwam $(n=9)$ of de ouders de verkeerde vragenlijst hadden ontvangen $(n=3)$. Daarnaast worden bij GGD Hollands Midden de Van Wiechenkenmerken op de contactmomenten 9 en 11 maanden (39 en 52 weken) alleen afgenomen wanneer het kind mogelijk extra zorg behoeft. Hierdoor konden de scores van de professionals van respectievelijk slechts negen en acht kinderen gekoppeld worden op deze contactmomenten. Voor 1 kind van 11 maanden kwam de geboortedatum niet overeen, dus het ontbreken van gegevens van de professional leidde tot 17 exclusies. De steekproefgrootte voor de tweede onderzoeksvraag was 182 kinderen.

\section{Ervaringen van ouders}

Bijna alle ouders (92\%) hadden plezier in het afnemen van alle Van Wiechenkenmerken (tab. 1). Daarnaast gaven sommige ouders ook in de open vragen nogmaals aan het leuk te vinden om op deze manier bezig te zijn en contact te hebben met hun kind.

Tevens zijn drie vragen gesteld over de duidelijkheid van de kenmerken. Hierbij geeft $92 \%$ van de ouders aan alle kenmerken duidelijk te vinden, 95\% van de ouders kon de instructies van alle kenmerken

Tabel 1 Antwoorden op de gesloten vragen over de ervaringen van ouders bij het zelf afnemen van de Van Wiechenkenmerken

\begin{tabular}{|c|c|c|}
\hline vraag & antwoorden & $n(\%)$ \\
\hline \multirow{4}{*}{$\begin{array}{l}\text { Vond u het leuk om } \\
\text { de testjes met uw } \\
\text { kind uit te voeren? }\end{array}$} & ja, alle testjes waren leuk om te doen & $194(92)$ \\
\hline & $\begin{array}{l}\text { sommige testjes waren leuk om te } \\
\text { doen }\end{array}$ & $9(4)$ \\
\hline & $\begin{array}{l}\text { nee, geen enkel testje was leuk om te } \\
\text { doen }\end{array}$ & $4(2)$ \\
\hline & onbekend & $4(2)$ \\
\hline \multirow{4}{*}{$\begin{array}{l}\text { Was het duidelijk } \\
\text { wat u moest doen } \\
\text { bij de testjes? }\end{array}$} & ja, alle testjes waren duidelijk & $195(92)$ \\
\hline & sommige testjes waren duidelijk & $15(7)$ \\
\hline & nee, geen enkel testjes was duidelijk & 0 \\
\hline & onbekend & $1(1)$ \\
\hline \multirow{4}{*}{$\begin{array}{l}\text { Kon u de instructies } \\
\text { volgen? }\end{array}$} & ja, bij alle testjes & $202(95)$ \\
\hline & bij sommige testjes lukte het & $8(4)$ \\
\hline & nee, het lukte bij geen enkel testje & 0 \\
\hline & onbekend & $1(1)$ \\
\hline \multirow{4}{*}{$\begin{array}{l}\text { Kon u de vragen na } \\
\text { afloop van de } \\
\text { testjes goed } \\
\text { beantwoorden? }^{\text {a }}\end{array}$} & $\begin{array}{l}\text { ja, alle vragen waren goed te beant- } \\
\text { woorden }\end{array}$ & $185(88)$ \\
\hline & $\begin{array}{l}\text { sommige vragen waren makkelijk te } \\
\text { beantwoorden }\end{array}$ & $24(11)$ \\
\hline & $\begin{array}{l}\text { nee, geen enkele vraag was makkelijk } \\
\text { te beantwoorden }\end{array}$ & 0 \\
\hline & onbekend & $2(1)$ \\
\hline
\end{tabular}

${ }^{a} 0 p$ de vragenlijst is in overleg met de GGD voor het woord 'test' gekozen, omdat dit beter aansluit bij ouders dan bijvoorbeeld het woord 'kenmerk'. 
Tabel 2 Proportionele overeenkomst in scores van de ouder en de professional op de geselecteerde Van Wiechenkenmerken

\begin{tabular}{|c|c|c|c|c|c|c|}
\hline kenmerk & $\begin{array}{l}\text { prof: - } \\
\text { ouder: - } \\
n\end{array}$ & $\begin{array}{l}\text { prof: - } \\
\text { ouder: + } \\
n\end{array}$ & $\begin{array}{l}\text { prof: }+ \\
\text { ouder: - } \\
n\end{array}$ & $\begin{array}{l}\text { prof: }+ \\
\text { ouder: + } \\
n\end{array}$ & $\begin{array}{l}\text { NA } \\
n\end{array}$ & $\begin{array}{l}\text { overeenkomst }^{\mathrm{a}} \\
\%\end{array}$ \\
\hline \multicolumn{7}{|l|}{4 weken $(n=34)$} \\
\hline ogen fixeren (FM) & 0 & 0 & 7 & 27 & 0 & 79 \\
\hline reageert op toespreken (C) & 0 & 0 & 3 & 31 & 0 & 91 \\
\hline beweegt armen evenveel (GM) & 0 & 0 & 7 & 21 & 6 & 72 \\
\hline beweegt benen evenveel (GM) & 0 & 0 & 4 & 24 & 6 & 86 \\
\hline \multicolumn{7}{|l|}{8 weken $(n=28)$} \\
\hline volgt met ogen èn hoofd (FM) & 2 & 1 & 1 & 23 & 1 & 93 \\
\hline lacht terug (C) & 1 & 1 & 0 & 25 & 1 & 96 \\
\hline beweegt armen evenveel (GM) & 0 & 0 & 6 & 13 & 9 & 68 \\
\hline beweegt benen evenveel (GM) & 0 & 0 & 4 & 15 & 9 & 79 \\
\hline \multicolumn{7}{|l|}{13 weken $(n=35)$} \\
\hline kijkt naar eigen handen (FM) & 5 & 1 & 4 & 22 & 3 & 84 \\
\hline maakt geluiden terug $(\mathrm{C})$ & 0 & 0 & 0 & 34 & 1 & 100 \\
\hline beweegt armen evenveel (GM) & 0 & 0 & 6 & 22 & 7 & 79 \\
\hline beweegt benen evenveel (GM) & 0 & 0 & 4 & 25 & 6 & 86 \\
\hline heft in buikligging hoofd tot $45^{\circ}(\mathrm{GM})$ & 2 & 1 & 11 & 20 & 1 & 65 \\
\hline \multicolumn{7}{|l|}{26 weken $(n=34)$} \\
\hline pakt in rugligging voorwerp binnen bereik (FM) & 1 & 1 & 9 & 21 & 2 & 69 \\
\hline speelt met handen middenvoor (FM) & 0 & 0 & 6 & 27 & 1 & 82 \\
\hline beweegt armen evenveel (GM) & 0 & 0 & 5 & 23 & 6 & 68 \\
\hline beweegt benen evenveel (GM) & 0 & 0 & 3 & 25 & 6 & 74 \\
\hline kijkt rond met $90^{\circ}$ geheven hoofd (GM) & 2 & 0 & 16 & 14 & 2 & 50 \\
\hline \multicolumn{7}{|l|}{39 weken $(n=9)^{b}$} \\
\hline \multicolumn{7}{|l|}{52 weken $(n=8)^{b}$} \\
\hline \multicolumn{7}{|l|}{65 weken $(n=34)$} \\
\hline doet blokje in/uit doos (FM) & 1 & 1 & 4 & 26 & 2 & 84 \\
\hline speelt 'geven en nemen' (FM) & 0 & 1 & 2 & 31 & 0 & 91 \\
\hline zegt 2 'geluidswoorden' met begrip (C) & 4 & 4 & 9 & 15 & 2 & 59 \\
\hline kruipt vooruit, buik vrij van de grond (GM) & 2 & 0 & 9 & 16 & 7 & 67 \\
\hline loopt langs (GM) & 3 & 0 & 3 & 24 & 4 & 90 \\
\hline
\end{tabular}

volgen en $88 \%$ kon alle vragen na afloop goed beantwoorden. De meest genoemde suggestie omtrent de helderheid van de testjes is om een tijdsindicatie voor het observeren aan de instructie toe te voegen. Verder werd door een aantal ouders aangegeven dat sommige kenmerken vrij te interpreteren zijn en er onduidelijkheden waren over de positie van de ouder tijdens het afnemen van het kenmerk. Sommige ouders hebben gesuggereerd dat video-instructies meer duidelijkheid verschaffen.

\section{Overeenkomst scores}

Voor de kenmerken waarbij er minstens 10 gekoppelde observaties zijn, liggen de proportionele overeenkomsten tussen de scores van de ouders en professional tussen de $50 \%$ en $100 \%$ (tab. 2). Vanwege het geringe aantal kinderen dat een kenmerk niet beheerst, is het percentage overeenkomst in feite een maat voor de specificiteit van de ouders (indien we aannemen dat de professionals de gouden standaard zijn) en kan met de huidige steekproefgrootte over de sensitiviteit voor het detecteren van ontwikkelingsachterstand geen uitspraak worden gedaan.

De proportionele overeenkomst is relatief hoog bij de communicatiekenmerken (C) en relatief laag bij de grove motoriekkenmerken (GM). Ter illustratie: 'Reageert op toespreken' (C, 4 weken) heeft een proportionele overeenkomst van $96 \%$ en 'Kijkt rond met $90^{\circ}$ geheven hoofd' (GM, 13 weken) een proportionele overeenkomst van $50 \%$.

In de Bland-Altman plot is de gemiddelde D-score van de ouder en professional voor een kind geplot tegen het verschil in D-score van de ouder en professio- 
Figuur 1 Bland-Altman Plot voor D-scores $(N=176)$

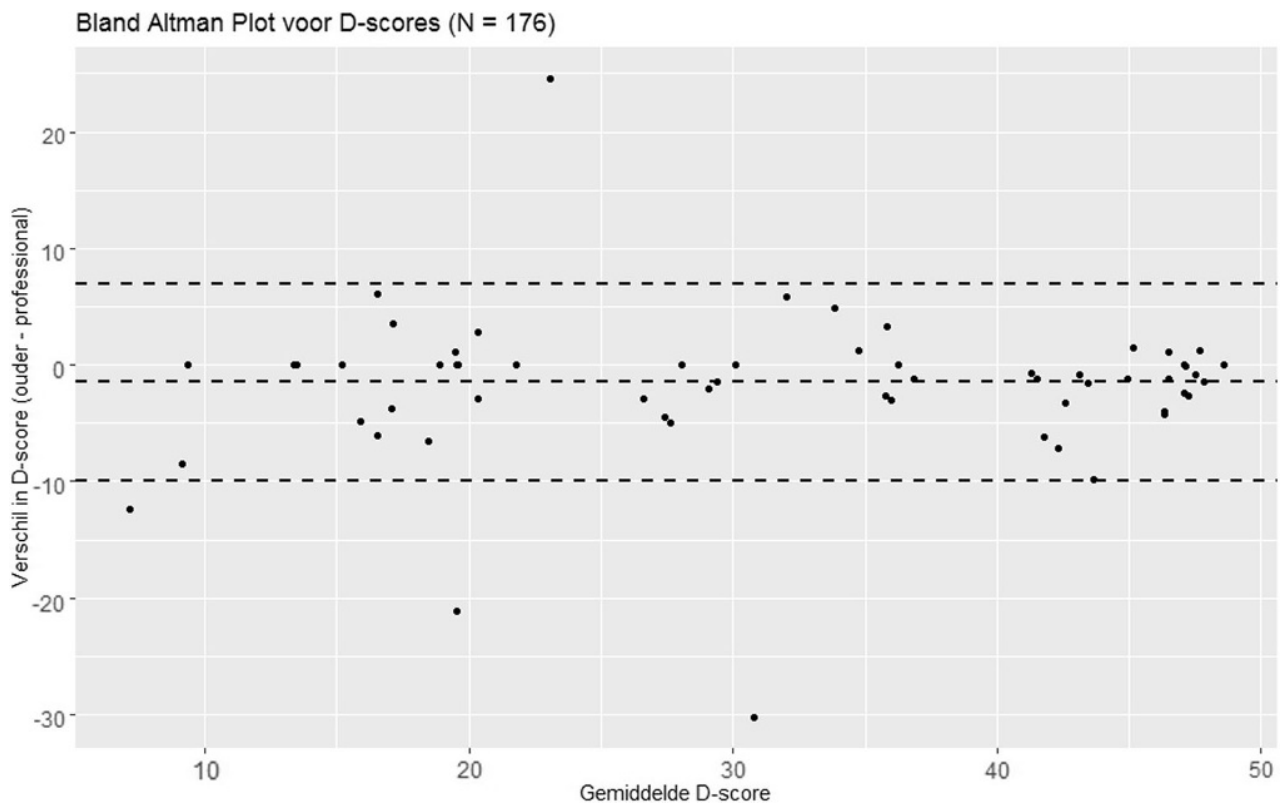

nal (zie fig. 1). Het gemiddelde van het verschil, gelijk aan $-1,48$ (95\%-betrouwbaarheidsinterval [BI]: $-2,12$, $-0,90)$, laat zien dat ouders over het algemeen genomen strenger oordelen dan de professional. Daarbij laat de Bland-Altman plot geen trend in de verschillen zien. Dit betekent dat het verschil in de D-scores constant is over de grootte van de D-score. Oftewel, de verschillen in D-score tussen ouder en professional zijn niet afhankelijk van de grootte van de D-score en daaruit volgend de leeftijd van het kind. De resultaten voor de 'limieten van de overeenkomst' zijn -10,09 (95\%-BI: $-14,90 ;-7,78)$ en 7,13 (95\%-BI: 5,03; 10,94). De limieten van de overeenkomst tonen een onzekerheid die klinisch van belang is: een verschil van 10 punten in $\mathrm{D}$-score kan leiden tot een andere conclusie omtrent de ontwikkeling van het kind.

\section{Discussie}

\section{Ervaringen van ouders}

Bijna alle ouders in de steekproef vinden het leuk om zelf de Van Wiechenkenmerken af te nemen bij hun kinderen en uit de opmerkingen en suggesties op de vragenlijst blijkt een groot enthousiasme en nieuwe inzichten bij sommige ouders. Het zelf afnemen van de kenmerken draagt bij aan een van de doelen van het Van Wiechenonderzoek: ouders betrekken bij de begeleiding van de ontwikkeling van hun kind [4]. Bovendien kan dit ook voor de JGZ extra mogelijkheden bieden: het gesprek tijdens het contactmoment kan op een andere manier verlopen als ouders zelf ook de kenmerken hebben afgenomen.

Suggesties die ouders gaven over de helderheid van de instructies leverden interessante punten op voor de doorontwikkeling van het materiaal, zoals het beschrijven van de observatietijd en de positie van de ouder ten opzichte van het kind. Daarnaast opperde een aantal ouders het gebruik van video-instructies. Voor professionals zijn dergelijke filmpjes al beschikbaar op de ledensite van het Van Wiechenonderzoek van het Nederlands Centrum Jeugdgezondheidszorg (NCJ). Deze zijn niet toegankelijk voor ouders, maar zouden mogelijk een aanknopingspunt kunnen zijn voor de doorontwikkeling van het instructiemateriaal voor ouders.

\section{Overeenkomst scores}

De proportionele overeenkomst tussen de scores op de Van Wiechenkenmerken varieerde tussen de verschillende kenmerken. Daarnaast leken de ouders over het algemeen strenger te zijn dan de professionals en leek er een verschil te zijn in de drie ontwikkelingsvelden. De proportionele overeenkomst op communicatiekenmerken (alle M-kenmerken) was relatief hoog, terwijl de overeenkomst relatief laag bleek voor grove motoriek. Dit zou deels verklaard kunnen worden door het feit dat de grove motoriekkenmerken veelal bestonden uit meerdere vragen voor de ouders die allemaal met 'ja' beantwoord moesten worden voor een positieve score. Een grotere steekproef is daarnaast noodzakelijk om de mate van overeenstemming (bovenop het toeval) tussen de scoring door ouders en professionals te kunnen bepalen.

Op basis van de Bland-Altman plot en de 'limieten van de overeenkomst' is het in deze studie moeilijk een eenduidige conclusie te trekken over de overeenkomst in D-scores van ouder(s) en professional. De $95 \%$-BI's van de 'limieten van de overeenkomst' zijn erg wijd, wat betekent dat er een grote onzekerheid over deze limieten is. Dit is ook deels veroorzaakt door vier uitschieters die een verschil van meer dan 10 punten hebben. Het is aannemelijk dat als er een groter 
aantal Van Wiechenkenmerken geselecteerd wordt de overeenstemming beter zal zijn.

\section{Beperkingen studie}

Deze studie kent enkele beperkingen, waarvan de steekproefgrootte de belangrijkste is. De studie is opgezet als een pilot, waardoor een beperkt aantal kinderen is uitgenodigd om deel te nemen. Verder was ook het aantal geselecteerde kenmerken vrij gering. Vanwege het hoge slagingspercentage op de Van Wiechenkenmerken is een grote steekproef nodig om genoeg kinderen te includeren die de kenmerken niet beheersen op de contactmomenten. De huidige studie is een eerste exploratie, die men behoedzaam moet interpreteren.

Bovendien hebben vooral hoogopgeleide moeders meegedaan met het onderzoek, wat mogelijk een vertekening oplevert. Bij een vervolgonderzoek dient ernaar gestreefd te worden meer laagopgeleide ouders en meer vaders te includeren.

\section{Vervolgonderzoek}

Deze pilotstudie biedt veel aanknopingspunten voor vervolgonderzoek. Dat vervolgonderzoek zou een grotere steekproef moeten hebben. Hierbij kan gedacht worden aan meer kinderen per contactmoment, meer kinderen van laagopgeleide ouders, maar ook het includeren van meer Van Wiechenkenmerken en meer contactmomenten van de JGZ. Het is denkbaar dat zelfafname door ouders en een afname door een professional weleens tot een betere inschatting van de ontwikkeling van een kind kan leiden dan afname door alleen een professional. Of dit zo is moet echter wel nog onderzocht worden.

Een andere vervolgrichting is de ontwikkeling van, en onderzoek naar, instructiemateriaal voor ouders. Het aanbieden van gepersonaliseerde feedback behoort daar ook toe.

Daarnaast is het interessant om te onderzoeken in hoeverre het zelf afnemen van de Van Wiechenkenmerken gebruikt kan worden in landen waar geen structuur van JGZ is.

We concluderen dat de ervaringen van ouders met het zelf afnemen van de Van Wiechenkenmerken positief zijn. Zelfafname kan hiermee bijdragen aan een van de doelen van het Van Wiechenonderzoek: ouders meer betrekken bij de ontwikkeling van hun kind. De proportionele overeenkomst op de kenmerken in deze pilotstudie laat een hoge overeenkomst zien op de communicatiekenmerken en een wat lagere overeenkomst op de grove motoriekkenmerken. Een groter onderzoek is noodzakelijk om uitspraak te kunnen doen over de betrouwbaarheid van de overeenkomst.
Dankbetuiging We bedanken alle betrokken professionals van GGD Hollands Midden voor hun bijdrage aan het onderzoek.

\section{Literatuur}

1. Nederlands Centrum Jeugdgezondheid. Landelijk Professioneel Kader: Uitvoering basispakket jeugdgezondheidszorg (JGZ). Utrecht: NCJ; 2015.

2. Jacobusse G, Buuren S van, Verkerk P. An interval scale for development of children aged 0-2 years. Stat Med. 2006;25:2272-83.

3. Jacobusse G, Buuren S van, Verkerk P. Ontwikkeling van de Dscore: een samenvattende maat voor hetVan Wiechenonderzoek. Tijdschr Jeugdgezondheidsz. 2008;40:11-4.

4. Laurent de Angulo M, Brouwers-de Jong E, Bijlsma-Schlösser J, Bulk-Bunschoten A, Pauwels J, Steinbuch-Linstra I. Ontwikkelings-onderzoek in de jeugdgezondheidszorg. Het Van Wiechenonderzoek-DeBaeckeFassaertMotoriektest. Assen: Van Gorcum; 2005.

5. Rydz D, Shevell M, Majnemer A, Oskoui M. Topical review: developmental screening. JChild Neurol. 2005;20:4-21.

6. Bricker D, Squires J, Kaminski R, Mounts L. The validity, reliability, and cost of a parent-completed questionnaire system to evaluate at-risk infants. J Pediatr Psychol. 1988;13:55-68.

7. Bricker D, Squires J. The effectiveness of parental screening of at-risk infants. Topics Early Child Spec Educ. 1989;9:67-85.

8. Glascoe F, Altermeier W, MacLean W. The importance of parents' concerns about their child's development. Arch Pediatr Adolesc Med. 1989;143:955-8.

9. Glascoe F, Dworkin P. The role of parents in the detection of developmental and behavioral problems. Pediatrics. 1995;95:829-36.

10. Glascoe F, Cunningham R. Parents' concerns about children's development: prescreening technique or screening test? Pediatrics. 1997;99:522-8.

11. Herngreen W, Reerink J, Noord-Zaadstra B van, VerlooverVanhorick S, Ruys J. SMOCC: design of a representative cohort-study of live-born infants in the Netherlands. Eur J Public Health. 1992;2:117-22.

12. Bouter L, Dongen M, Zielhuis G, Zeegers M. Leerboek epidemiologie. Houten: Bohn Stafleu Van Loghum; 2016.

13. Bland J, Altman D. Statistical methods for assessing agreement between two methods of clinical measurement. Int J Nurs Stud. 2010;47:931-6.

14. Barlett J, Frost C. Reliability, repeatability and reproducibility: analysis of measurement errors in continuous variables. Ultrasound Obstet Gynecol. 2008;31:466-75.

M. Grevinga, scientist innovator/data analist

L.V. van Harten, consultant

H. Hofstetter, statisticus

P.H. Verkerk, arts $M \& G$, jeugdarts \& epidemioloog

S.B. Detmar, principal advisor 